\title{
Visceral adiposity index and DHEAS are useful markers of diabetes risk in women with polycystic ovary syndrome
}

\author{
M C Amato, A Magistro, G Gambino, R Vesco and C Giordano
}

Biomedical Department of Internal and Specialist Medicine (Di.Bi.M.I.S.), Section of Cardio-Respiratory and Endocrine-Metabolic Diseases, University of Palermo, Piazza delle Cliniche 2, Palermo 90127, Italy

\author{
Correspondence \\ should be addressed \\ to C Giordano \\ Email \\ carla.giordano@unipa.it
}

\begin{abstract}
Objective: On the basis of the known diabetes risk in polycystic ovary syndrome (PCOS), recent guidelines of the Endocrine Society recommend the use of an oral glucose tolerance test (OGTT) to screen for impaired glucose tolerance (IGT) and type 2 diabetes (T2DM) in all women with PCOS. However, given the high prevalence of PCOS, OGTT would have a high cost-benefit ratio. In this study, we identified, through a receiver operating characteristic analysis, simple predictive markers of the composite endpoint (impaired fasting glucose (IFG) or IGT or IFG + IGT or T2DM) in women with PCOS according to the Rotterdam criteria.

Design: We conducted a cross-sectional study of 241 women with PCOS in a university hospital setting.

Methods: Clinical, anthropometric, and metabolic (including OGTT) parameters were evaluated. The homeostasis model assessment of insulin resistance (HOMA2-IR), the Matsuda index of insulin sensitivity, and the oral dispositional index and visceral adiposity index (VAl) were determined.

Results: Out of 241 women included in this study, 28 (11.6\%) had an IFG, $13(5.4 \%)$ had IGT, four (1.7\%) had IFG + IGT, and four $(1.7 \%)$ had T2DM. Among the anthropometric variables examined, the VAI had a significantly higher C-statistic compared with BMI $(0.760(95 \% \mathrm{Cl}: 0.70-0.81)$ vs $0.613(95 \% \mathrm{Cl}: 0.54-0.67) ; P=0.014)$ and waist circumference $(0.760(95 \% \mathrm{Cl}$ : $0.70-0.81)$ vs $0.619(95 \% \mathrm{Cl}: 0.55-0.68) ; P=0.028)$. Among all the hormonal and metabolic serum variables examined, DHEAS showed the highest C-statistic $(0.720$ (95\% Cl: $0.65-0.77) ; P<0.001)$.

Conclusions: In addition to fasting glucose, the VAI and DHEAS may be considered useful tools for prescreening in all women with PCOS without the classical risk factors for diabetes.

\section{Introduction}

Polycystic ovary syndrome (PCOS) is the most common endocrine disorder among women of reproductive age, with a prevalence of between 5 and 20\% (according to the diagnostic criteria used) $(1,2,3)$. In addition to chronic anovulation and hyperandrogenism (clinical and biochemical), PCOS is also associated with insulin resistance $(4,5)$ and an increased risk of glucose intolerance and type 2 diabetes mellitus (T2DM) $(6,7,8)$, dyslipidemia, subclinical atherosclerosis, and vascular dysfunction, independently of BMI (5). It is known that women with
PCOS have a five- to tenfold increased risk of developing T2DM $(6,7,8)$.

Owing to this high risk of impaired glucose tolerance (IGT) and T2DM in women with PCOS (even without impaired fasting glucose (IFG)), periodic screening of patients to detect early abnormalities in glucose tolerance is recommended by several scientific organizations, although a time interval for screening has not been specified $(9,10,11)$.

The Endocrine Society has recently issued clinical practice guidelines on the diagnosis and treatment of

Published by Bioscientifica Ltd 
PCOS (12), in which they recommend the use of an oral glucose tolerance test (OGTT) (fasting and a 2-h glucose level using a $75 \mathrm{~g}$ oral glucose load) to screen for IGT and T2DM in all adolescents and adult women with PCOS because they are at high risk for such abnormalities. Rescreening is suggested every 3-5 years, or more frequently if clinical factors such as central adiposity, substantial weight gain, and/or symptoms of diabetes develop.

This procedure, however, has its costs, given the high prevalence of PCOS, and especially its chronicity. In addition, we must also consider that the large phenotypic variability of PCOS (13), also influenced by environmental factors, may change during fertile life (changes in the degree of hyperandrogenism, menstrual dysfunction, weight, and insulin resistance). This implies that some women, even if they do not meet the full diagnostic criteria of PCOS at a given time, can nonetheless have a high risk of diabetes. In case of normal fasting glucose levels, it would be useful to have simple prescreening tools for diabetes, to be used both in overt PCOS and in the presence of a single diagnostic criterion of Rotterdam.

In the current study, through a receiver operating characteristic (ROC) analysis, we wanted to evaluate whether simple anthropometric and/or laboratory parameters may be predictive of the composite endpoint (IFG or IGT or IFG + IGT or T2DM) in women with PCOS (according to the Rotterdam criteria).

\section{Subjects and methods}

\section{Subjects}

This study was approved by the Institutional Review Board at the Faculty of Medicine of the University of Palermo. At the time of observation in our Gynecologic Outpatients Endocrinology Unit, all patients regularly signed an informed consent for the scientific use of their data. It involved a cross-sectional study of 340 consecutive Caucasian women, aged 14-44 years followed up in our outpatients clinic (from January 1st 2005 to December 31st 2013) for hirsutism and/or other signs and symptoms of hyperandrogenism (acne/seborrhea and alopecia) and/or irregular menstrual cycles (oligoamenorrhea). Applying the Rotterdam diagnostic criteria (14), we retrospectively selected 241 of these women (70.8\%) with PCOS.

The following subjects were excluded from the study: a small number of women (32/340 cases) with amenorrhea at the moment of observation (absence of vaginal bleeding $>6$ months), and those with various progesterone bleeding induction schemes, potentially interfering with sex hormone patterns; women treated with clomiphene citrate, oral contraceptives, antiandrogens, drugs to control their appetite or insulin-sensitizing drugs (metformin, pioglitazone, and rosiglitazone) during the 6 months before the first examination; women with hyperprolactinemia (5/340 cases); patients with $17-\mathrm{OH}$ progesterone levels $>6.05 \mathrm{nmol} / \mathrm{l}$ who, after $250 \mathrm{mg}$ Synacthen (synthetic analog of ACTH), showed 17-OH progesterone $>30.26 \mathrm{nmol} / 1$ at $60 \mathrm{~min}$ (3/340 cases); women with DHEAS $>16.32 \mathrm{mmol} / \mathrm{l}$, who, when screened with a computerized axial tomography scan, presented adrenal hyperplasia or adenoma or virilizing androgensecreting neoplasias (1/340 cases); and women whose clinical and hormone evaluation (phenotype, increased 24-h free urinary cortisol, and high cortisol levels after $1 \mathrm{mg}$ of overnight dexamethasone) suggested Cushing's syndrome (4/340 cases). Women with hypo- or hyperthyroidism were also not taken into consideration for the study. Out of 340 women, 54 were excluded because, according to the Rotterdam criteria, they had only one diagnostic criterion for PCOS.

The following relevant data were obtained from our database: a possible family history of diabetes, oligoamenorrhea, hirsutism, acne, and age of menarche; weight, BMI, waist circumference (WC), blood pressure, and Ferriman-Gallwey (FG) score. It is a routine practice in our Gynecologic Outpatients Endocrinology Unit to evaluate the degree of hirsutism using the FG map scoring system, which divides the body up into 11 domains. Hirsutism was defined as an FG score $>8$ (15). The patients were tested for FSH, LH, 17 $\beta$-estradiol $\left(\mathrm{E}_{2}\right)$, 17-OH progesterone, basal prolactin, total testosterone, DHEAS, $\Delta 4$-androstenedione, and sex hormone-binding globulin (SHBG), during the follicular phase (day 7 from the beginning of the last period). On the same day, we also tested for total cholesterol, HDL cholesterol, LDL cholesterol, triglycerides, glutamic-pyruvic transaminase (GPT), glutamic-oxaloacetic transaminase (GOT), and uric acid, performed an OGTT (75 g glucose), and measured glycemia and insulinemia at $0,30,60,90$, and $120 \mathrm{~min}$. Serum progesterone level was determined between days 20 and 24 of the menstrual cycle and chronic oligoanovulation was established if two consecutive cycles were anovulatory (progesterone level $<3 \mathrm{ng} / \mathrm{ml}$ (international system (SI): $<9.54 \mathrm{nmol} / \mathrm{l}$ )) (16). Biochemical hyperandrogenism was diagnosed when the androgen levels were as follows: total 
testosterone $>2.84 \mathrm{nmol} / \mathrm{l}$, DHEAS $>12.14 \mathrm{mmol} / \mathrm{l}$, and $\Delta 4$-androstenedione $>10.72 \mathrm{nmol} / 1$ (calculated on the basis of the 95th percentile upper limits of basal serum androgen normality in 144 healthy Sicilian eumenorrheal women without hirsutism and a family history of PCOS (used as a control group in our previous study (17))). Transvaginal ovarian ultrasound scanning was performed between days 5 and 10 from the beginning of the last period using a $7.5-\mathrm{MHz}$ vaginal probe transducer (General Electric LOGIQ 400MD, Milwaukee, WI, USA). Both ovaries were measured in the sagittal, transverse, and coronal planes. Ovaries were classified as polycystic if 12 or more follicles measuring $2-8 \mathrm{~mm}$ in diameter were present in each ovary, and/or there was an increase in the ovarian volume ( $>10 \mathrm{ml})(18)$.

Metabolic syndrome (MetS) was diagnosed according to the National Cholesterol Education Program Adult Treatment Panel (NCEP-ATP) III definition (19) and diagnosis of diabetes mellitus according to the recommendations of the American Diabetes Association (20). Patients with prediabetes were defined as having IFG (fasting plasma glucose (FPG) levels 5.6-6.9 mmol/l), or IGT (2-h after OGTT plasma glucose levels of 7.8-11.0 mmol/l), or IFG + IGT.

\section{Assays}

All hormones were measured in our laboratory using commercial kits. These included ELISA (DRG Diagnostics, DRG Instruments $\mathrm{GmbH}$, Marburg, Germany) for FSH (mUI/ml; analytical sensitivity: $0.85 \mathrm{mUI} / \mathrm{ml}$; the intra- and interassay CV values were 4.50 and $5.84 \%$ respectively), $\mathrm{LH}$ (mUI/ml; analytical sensitivity: $1.27 \mathrm{mUI} / \mathrm{ml}$; the intra- and interassay $\mathrm{CV}$ values were 4.54 and $3.22 \%$ respectively), $17 \beta-\mathrm{E}_{2}(\mathrm{pg} / \mathrm{ml}$; analytical sensitivity: $9.71 \mathrm{pg} / \mathrm{ml}$; the intra- and interassay $\mathrm{CV}$ values were 2.71 and $6.72 \%$ respectively), $17-\mathrm{OH}$ progesterone (ng/ml; analytical sensitivity: $0.034 \mathrm{ng} / \mathrm{ml}$; the intra- and interassay $\mathrm{CV}$ values were 5.40 and $6.17 \%$ respectively), $\mathrm{Pg}(\mathrm{ng} / \mathrm{ml}$; analytical sensitivity: $0.045 \mathrm{ng} / \mathrm{ml}$; the intra- and interassay $\mathrm{CV}$ values were 5.40 and 4.34 respectively), PRL ( $\mathrm{ng} / \mathrm{ml}$; analytical sensitivity: $0.35 \mathrm{ng} / \mathrm{ml}$; the intra- and interassay $\mathrm{CV}$ values were 2.91 and $5.64 \%$ respectively), total testosterone ( $\mathrm{ng} / \mathrm{ml}$; analytical sensitivity: $0.083 \mathrm{ng} / \mathrm{ml}$; the intra- and interassay CV values were 3.28 and $4.73 \%$ respectively), $\Delta 4$-androstenedione ( $\mathrm{ng} / \mathrm{ml}$; Arnika, Milan, Italy; analytical sensitivity: $0.021 \mathrm{ng} / \mathrm{ml}$; the intra- and interassay $\mathrm{CV}$ values were 5.30 and $8.10 \%$ respectively)), and insulin (mUI/l; the intra- and interassay $\mathrm{CV}$ values were $\leq 4$ and $\leq 3.6 \%$ respectively). Chemiluminescence assays were used for DHEAS ( $\mu \mathrm{g} / \mathrm{dl}$; Immulite, Diagnostic Products, Genoa, Italy; analytical sensitivity: $15 \mu \mathrm{g} / \mathrm{dl}$; the intra- and interassay CV values were 6.30 and $6.90 \%$ respectively) and serum SHBG (nmol/l; Immulite, Diagnostic Products, Genoa, Italy; analytical sensitivity: $0.015 \mathrm{nmol} / \mathrm{l}$; the intra- and interassay $\mathrm{CV}$ values were 5.50 and $6.20 \%$ respectively). Blood glucose levels $(\mathrm{mg} / \mathrm{dl})$ were measured using an electrochemical system (Glucocard, Menarini Diagnostics, Florence, Italy). Total cholesterol, HDL, triglycerides, GOT, GPT, and uric acid were measured in our laboratory using standard assays. LDL cholesterol levels were calculated with Friedewald's formula. The conversion factors for the SI were the following: glucose (mg/dl vs $\mathrm{mmol} / \mathrm{l}: 0.0555)$, insulin (mUI/l vs pmol/l: 6.945), total cholesterol (mg/dl vs $\mathrm{mmol} / \mathrm{l}$ : 0.0259), total testosterone ( $\mathrm{ng} / \mathrm{ml}$ vs $\mathrm{nmol} / \mathrm{l}$ : 3.467), free testosterone (pg/ml vs pmol/l: 3.47), DHEAS ( $\mu \mathrm{g} / \mathrm{dl}$ vs mmol/l: 0.0272), $\Delta 4$-androstenedione (ng/ml vs nmol/l: 3.492), $\mathrm{E}_{2}$ (pg/ml vs $\left.\mathrm{pmol} / \mathrm{l}: 3.671\right), 17-\mathrm{OH}$ progesterone ( $\mathrm{ng} / \mathrm{ml}$ vs $\mathrm{nmol} / \mathrm{l}: 3.026), \mathrm{Pg}(\mathrm{ng} / \mathrm{ml}$ vs nmol/l: 3.180), PRL (ng/ml vs $\mu \mathrm{g} / \mathrm{l}: 1)$, FSH (mUI/ml vs IU/l: 1$)$, and LH (mUI/ml vs IU/l: 1$)$.

Free androgen index was calculated as the ratio of total testosterone levels in $\mathrm{nmol} / \mathrm{l}$ to $\mathrm{SHBG}$ levels in nmol/lt $\times 100(\%)(21)$. Insulin sensitivity was estimated indirectly using fasting plasma insulin and FPG to calculate the homeostasis model of insulin resistance (HOMA2-IR) (calculations were performed using a free software provided by the University of Oxford Diabetes Trial Unit (http://www.dtu.ox.ac.uk/homacalculator)) and using glucose and insulin values during the OGTT to calculate the Matsuda index of insulin sensitivity (ISI Matsuda) (22) (10 000/glucose (mg/dl) $\times$ insulin $(\mu \mathrm{U} / \mathrm{ml}) \times$ glucose mean $\times$ insulin mean). A composite measure of $\beta$-cell function relative to insulin sensitivity, assessed by oral disposition index (DIO) (23), was calculated as $\left(\Delta\right.$ Insulin $_{0-30} / \Delta$ Glucose $\left._{0-30}\right) \times(1 /$ fasting insulin). The trapezoidal method was used for the calculation of the areas under the curves for insulin $\left(\mathrm{AUC}_{2 \mathrm{~h} \text { insulin }}\right)$ and glucose $\left(\mathrm{AUC}_{2} \mathrm{~h}\right.$ glucose$)$.

The visceral adiposity index (VAI) was calculated as described (24) using the following sex-specific equations:

where TG is triglyceride levels expressed in $\mathrm{mmol} / \mathrm{l}$ and HDL is HDL cholesterol levels expressed in $\mathrm{mmol} / \mathrm{l}$.

Females : $\mathrm{VAI}=\left(\frac{\mathrm{WC}}{36.58+(1.89 \times \mathrm{BMI})}\right) \times\left(\frac{\mathrm{TG}}{0.81}\right) \times\left(\frac{1.52}{\mathrm{HDL}}\right)$. 


\section{Statistical analysis}

The Statistical Packages for Social Sciences SPSS version 17 were used for the explorative data analysis. Baseline characteristics were expressed as mean \pm s.D. and range for continuous variables; rates and proportions were calculated for categorical data. The normality of distribution for quantitative variables was assessed using the Shapiro-Wilk test. Differences between Groups A and B in univariate analysis were detected by unpaired Student's $t$ test for continuous variables (after testing for equality of variance: Levene's test) and by the $\chi^{2}$-test and Fisher's exact test (when appropriate) for categorical variables. For comparison between Groups A and B, the group sizes provided $90 \%$ power to detect a moderate effect size (Cohen's $d=0.5$ ) using the $T$-test, with $\alpha$ error at 0.05. Post-hoc power analysis was performed using the G*Power Version 3.1.6 Software. The ROC curve analysis was conducted using the MedCalc software v. 9.3.8.0 for Windows (which uses calculation of the area under the curve (C-statistic) and 95\% CIs by the technique of Hanley and McNeil), to evaluate the diagnostic performance of the various parameters (BMI, WC, total testosterone, DHEAS, total cholesterol, non-HDL cholesterol, triglycerides, uric acid, and VAI) for predicting an altered glucose tolerance (IFG or IGT or IFG+IGT or T2DM). The differences between C-statistics were calculated by the method of Hanley and McNeil.

Some linear regression models were performed in order to correct the correlations between DHEAS and the various indices of insulin resistance for age and BMI. A $P$ value of $<0.05$ was considered statistically significant.

\section{Results}

The demographic, clinical, and biochemical characteristics (including anthropometric measurements, hormonal profile, and metabolic profile) of the 241 women with PCOS are presented in Table 1 . The prevalence of alterations in glucose tolerance was as follows: IFG 28/241 (11.6\%), IGT 13/241 (5.4\%), IGT+IGT 4/241 (1.7\%), and T2DM 4/241 (1.7\%). The composite endpoint (IFG or IGT or IFG + IGT or T2DM) was present in 49 women with PCOS (20.3\%) (Group B) (Table 2).

The remaining 192 women who had normal glucose tolerance (Group A) showed a significantly lower BMI and a WC compared with Group B $(29.54 \pm 6.97$ vs $31.87 \pm$ $6.22 \mathrm{~kg} / \mathrm{m}^{2}, P=0.025 ; 90.41 \pm 17.48$ vs $97.01 \pm 16.40 \mathrm{~cm}$, $P=0.015$ respectively). Group $B$ showed a higher
Table 1 Clinical, anthropometric and biochemical characteristics of the 241 women with $\mathrm{PCOS}^{\mathrm{a}}$. Data are presented as mean \pm s.D. (range) or as $n(\%)$.

\section{Characteristics \\ Age (years)}

BMI $\left(\mathrm{kg} / \mathrm{m}^{2}\right)$

Age of menarche (years)

Waist circumference $(\mathrm{cm})$

Waist-to-hip ratio (WHR)

FG score

Classes of obesity

Underweight

Normal weight

Overweight

Obese class I

Obese class II

Obese class III

Cigarette smoking

Dyslipidemia

Increased non-HDL-C: $>4.14 \mathrm{mmol} / \mathrm{l}^{\mathrm{C}}$

Increased LDL-C: $>3.37 \mathrm{mmol} / \mathrm{l}^{\mathrm{c}}$

Metabolic syndrome ${ }^{d}$

Diabetes or fasting glucose $\geq 5.6$ $\mathrm{mmol} / \mathrm{l}$

High blood pressure ( $\geq 130 / 85 \mathrm{mmHg}$ )

High triglycerides $(\geq 1.7 \mathrm{mmol} / \mathrm{l})$

Low HDL cholesterol $(<1.04 \mathrm{mmol} / \mathrm{l})$

Increased WC ( $>88 \mathrm{~cm})$

Impaired fasting glucose (IFG)

Impaired glucose tolerance (IGT)

IFG + IGT

Diabetes mellitus

Hormonal profiles

FSH (IU/I)

$\mathrm{LH}(\mathrm{IU} / \mathrm{l})$

$17 \beta-\mathrm{E}_{2}(\mathrm{pmol} / \mathrm{l})$

17OHPg (nmol/l)

$\mathrm{Pg}(\mathrm{nmol} / \mathrm{l})$

Total testosterone $(\mathrm{nmol} / \mathrm{l})$

SHBG (nmol/l)

FAI $(100 \times($ Total Testosterone/ SHBG)) (\%)

DHEA-S $(\mu \mathrm{mol} / \mathrm{l})$

$\Delta 4$ androstenedione $(\mathrm{nmol} / \mathrm{l})$

Metabolic profiles

Homa2-IR

ISI Matsuda

$\mathrm{AUC}_{2} \mathrm{~h}$ insulin (pmol/l per $120 \mathrm{~min}$ )

$A_{U} C_{2}$ h glucose $(\mathrm{mmol} / /$ per $120 \mathrm{~min}$ )

Oral dispositional index (DIo)

VAl

Total cholesterol $(\mathrm{mmol} / \mathrm{l})$

HDL cholesterol ( $\mathrm{mmol} / \mathrm{l})$

Calculated LDL cholesterol $(\mathrm{mmol} / \mathrm{l})$

Non-HDL cholesterol (mmol/l)

Triglycerides $(\mathrm{mmol} / \mathrm{l})$

Uric acid ( $\mu \mathrm{mol} / \mathrm{l})$

Glutamic oxaloacetic transaminase (GOT) (U/I)

Glutamic pyruvate

transaminase (GPT) (U/l)

\begin{tabular}{c}
\hline Values \\
\hline $24.39 \pm 6.17(14-43)$ \\
$30.01 \pm 6.87(18-50)$ \\
$11.93 \pm 1.40(9-17)$ \\
$91.75 \pm 17.44(54-138)$ \\
$0.82 \pm 0.09(0.59-1.17)$ \\
$13.31 \pm 6.92(1-35)$
\end{tabular}

$4(1.7 \%)$

$67(27.8 \%)$

$67(27.8 \%)$

$43(17.8 \%)$

$40(16.6 \%)$

$20(8.3 \%)$

$42(17.4 \%)$

$83(34.4 \%)$

$57(23.7 \%)$

$39(16.2 \%)$

$31(12.9 \%)$

$14(5.8 \%)$

$36(14.9 \%)$

$96(39.8 \%)$

$131(54.4 \%)$

$28(11.6 \%)$

$13(5.4 \%)$

$4(1.7)$

$4(1.7 \%)$

$6.60 \pm 2.78(1.00-21.70)$

$8.38 \pm 4.53(0.30-24.00)$

$191.81 \pm 99.29(30.95-587.36)$

$4.35 \pm 2.91(0.51-20.58)$

$12.55 \pm 17.43(0.29-89.68)$

$2.22 \pm 1.43(0.07-11.09)$

$68.42 \pm 42.48(10.00-200.00)$

$5.31 \pm 5.98(0.18-42.49)$

$8.00 \pm 4.99(1.33-23.61)$

$9.79 \pm 6.91(1.05-45.40)$

$2.28 \pm 1.33(0.40-7.20)$

$3.83+3.00(0.25-23.00)$

$11090 \pm 6870$ (762-36 540)

$765+148$ (477-1401)

$4.27 \pm 11.47(0.05-96.10)$

$1.82+1.06(0.19-5.96)$

$5.21 \pm 1.19(2.94-11.56)$

$1.32 \pm 2.28(0.17-2.19)$

$3.00 \pm 1.07(0.95-8.85)$

$3.88 \pm 1.21(1.60-10.58)$

$1.18+0.55(0.29-4.35)$

$4.23 \pm 1.69(1.8-9.6)$

$21.13 \pm 7.74(11.00-68.00)$

$24.72 \pm 14.91(7.00-129.00)$

aAccording to Rotterdam Consensus 2003 (ESHRE/ASRM)

${ }^{b}$ WHO classification (2010).

'According to Consensus Statement (AE-PCOS) Society (Wild et al. (34)).

${ }^{\mathrm{d}}$ According to Adult Treatment Panel (ATP) III criteria. 
Table 2 Clinical, anthropometric, and biochemical differences between women with PCOS and normal glucose tolerance (Group A) and women with PCOS and altered glucose tolerance (IFG or IGT or IFG + IGT or T2DM) (Group B). Data are presented as mean \pm s.D. or as $n(\%)$.

\begin{tabular}{|c|}
\hline 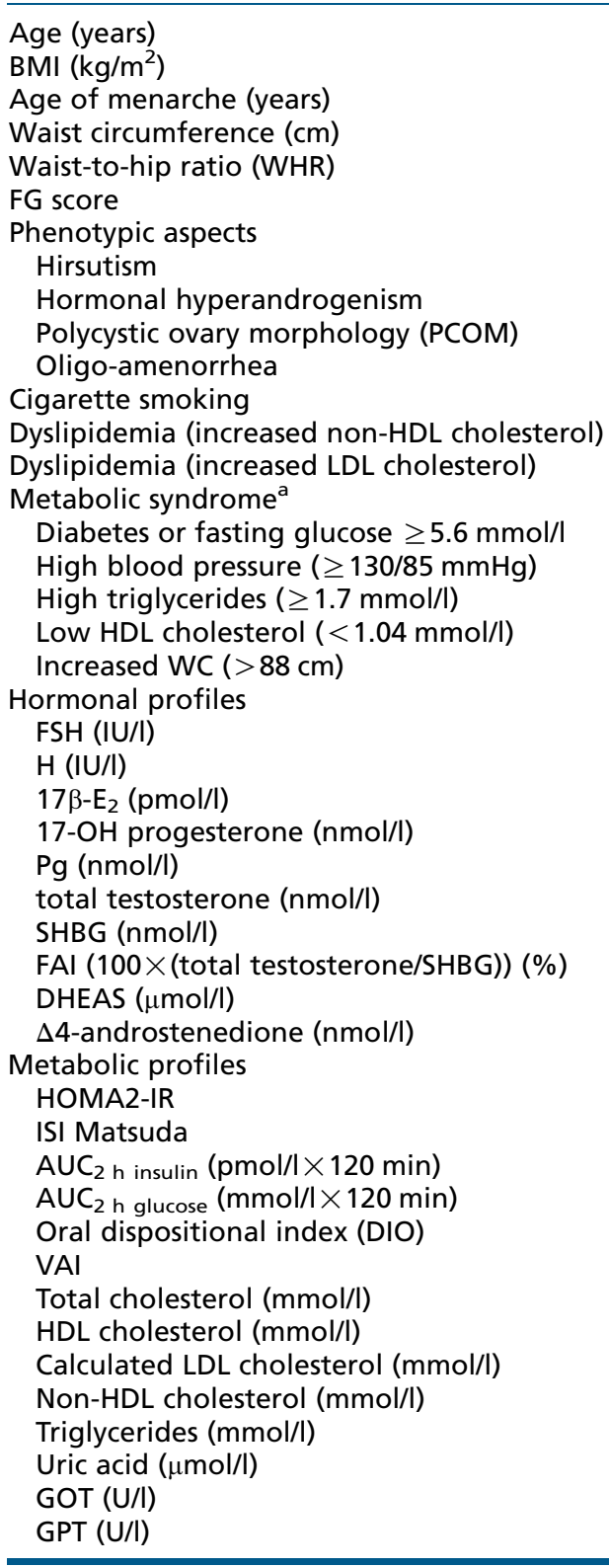 \\
\hline
\end{tabular}

G

Group A $(n=192)$
$24.08 \pm 6.17$
$29.54 \pm 6.97$
$11.98 \pm 1.45$
$90.41 \pm 17.48$
$0.82 \pm 0.09$
$13.22 \pm 7.05$

$142(74.0 \%)$

$94(49.0 \%)$

$146(76.0 \%)$

$140(72.9 \%)$

$36(18.8 \%)$

$58(30.2 \%)$

$39(20.3 \%)$

$20(10.4 \%)$

$9(4.7 \%)$

$24(12.5 \%)$

$68(35.4 \%)$

$96(50 \%)$

$6.50 \pm 2.43$

$8.27 \pm 4.41$

$194.29 \pm 102.45$

$4.15 \pm 2.83$

$13.56 \pm 18.22$

$2.12 \pm 1.26$

$70.12 \pm 42.51$

$4.99 \pm 5.73$

$7.31 \pm 4.07$

$9.20 \pm 5.68$

$2.18 \pm 1.26$

$4.06 \pm 3.10$

$10790 \pm 6841$

$728+104$

$3.11 \pm 5.19$

$1.63 \pm 0.93$

$5.12 \pm 1.03$

$1.34+0.28$

$2.94 \pm 1.07$

$3.78 \pm 1.04$

$1.14+0.49$

$4.00 \pm 1.53$

$20.68 \pm 6.75$

$23.71 \pm 12.83$

Grou

\begin{tabular}{c} 
Group B $(n=49)$ \\
\hline $25.61 \pm 6.05$ \\
$31.87 \pm 6.22$ \\
$11.77 \pm 1.19$ \\
$97.01 \pm 16.40$ \\
$0.83 \pm 0.10$ \\
$13.67 \pm 6.46$
\end{tabular}

\begin{tabular}{c}
\hline $\boldsymbol{P}$ \\
\hline 0.119 \\
0.025 \\
0.315 \\
0.015 \\
0.511 \\
0.667
\end{tabular}

$41(83.7 \%)$

$28(57.1 \%)$

$35(71.4 \%)$

$40(81.6 \%)$

$6(12.2 \%)$

$25(51.0 \%)$

$18(36.7 \%)$

$19(38.8 \%)$

$31(63.3 \%)$

$5(10.2 \%)$

$12(24.5 \%)$

$28(57.1 \%)$

$35(71.4 \%)$

$6.98 \pm 3.86$

$8.78 \pm 5.00$

$181.74 \pm 85.57$

$5.15 \pm 3.12$

$8.56 \pm 13.35$

$2.63 \pm 1.94$

$61.77 \pm 42.12$

$6.55 \pm 6.80$

$10.70 \pm 5.06$

$12.10 \pm 10.16$

$2.67 \pm 1.54$

$2.94 \pm 2.41$

$12266 \pm 6930$

$907 \pm 203$

$8.85 \pm 22.88$

$2.53 \pm 1.23$

$5.57 \pm 1.66$

$1.27 \pm 0.99$

$3.21 \pm 1.04$

$4.30 \pm 1.68$

$1.33+0.73$

$4.92 \pm 1.96$

$22.65 \pm 10.38$

$27.95 \pm 20.08$
0.156

0.306

0.505

0.210

0.284

0.006

0.016

$<0.001$

$<0.001$

0.141

0.036

0.006

0.007

0.300

0.532

0.395

0.056

0.080

0.027

0.221

0.145

$<0.001$

0.060

0.046

0.008

0.186

$<0.001$

0.002

$<0.001$

0.017

0.053

0.212

0.007

0.031

0.004

0.153

0.193

IFG, impaired fasting glucose; IGT, impaired glucose tolerance; T2DM, type 2 diabetes mellitus. ${ }^{\text {aAccording to ATP III criteria. }}$

prevalence of MetS (38.8\% vs $10.4 \%, P<0.001)$ and its individual components (except for high blood pressure; Table 2).

With regard to the hormonal profile, the only differences found between the two groups were significantly higher levels of total testosterone
$(2.63 \pm 1.94 \mathrm{nmol} / 1$ vs $2.12 \pm 1.26 \mathrm{nmol} / 1, \quad P=0.027)$ and DHEAS $(10.70 \pm 5.06 \mu \mathrm{mol} / \mathrm{l}$ vs $7.31 \pm 4.07 \mu \mathrm{mol} / \mathrm{l}$, $P<0.001)$ in Group B.

The metabolic profile of Group B was significantly altered compared with Group A, especially with regard to HOMA2-IR, ISI Matsuda, $\mathrm{AUC}_{2} \mathrm{~h}$ glucose, DIO, VAI, total 
Table 3 Optimal cutoff points of the various parameters able to predict an altered glucose tolerance (IFG or IGT or IFG + IGT or T2DM).

\begin{tabular}{|c|c|c|c|c|c|c|c|}
\hline & $\begin{array}{l}\text { Cutoff } \\
\text { point }\end{array}$ & Sens. $(\%)$ & Spec. $(\%)$ & $\begin{array}{l}\text { Area under } \\
\text { ROC curve }\end{array}$ & S.E.M. & $95 \% \mathrm{Cl}$ & $\boldsymbol{P}$ \\
\hline $\mathrm{BMI}$ & 28.4 & 71.43 & 53.13 & 0.613 & 0.046 & $0.54-0.67$ & 0.015 \\
\hline WC & 91 & 77.55 & 55.21 & 0.619 & 0.046 & $0.55-0.68$ & 0.011 \\
\hline Total testosterone & 1.38 & 87.76 & 32.29 & 0.556 & 0.047 & $0.49-0.62$ & 0.233 \\
\hline DHEAS & 8.43 & 71.43 & 69.79 & 0.720 & 0.044 & $0.65-0.77$ & $<0.001$ \\
\hline Total cholesterol & 5.98 & 32.65 & 88.54 & 0.558 & 0.047 & $0.49-0.62$ & 0.219 \\
\hline Non-HDL cholesterol & 4.97 & 32.65 & 91.67 & 0.578 & 0.047 & $0.51-0.64$ & 0.097 \\
\hline Triglycerides & 1.54 & 38.78 & 82.29 & 0.569 & 0.047 & $0.50-0.63$ & 0.142 \\
\hline Uric acid & 4.9 & 53.85 & 70.18 & 0.626 & 0.053 & $0.54-0.70$ & 0.019 \\
\hline VAI & 1.82 & 71.43 & 75.00 & 0.760 & 0.042 & $0.70-0.81$ & $<0.001$ \\
\hline
\end{tabular}

WC, waist circumference; VAI, visceral adiposity index. Sens., sensitivity; Spec., specificity.

cholesterol, non-HDL cholesterol, triglycerides, and uric acid (Table 2).

\section{ROC curve analysis}

Any variables that showed significant differences between the two groups (excluding those arising from the execution of an OGTT) were subjected to a ROC curve analysis in order to identify the optimal cutoff points associated with the composite endpoint (IFG or IGT or IFG + IGT or T2DM).

C-statistics were 0.613 (95\% CI $0.54-0.67 ; P=0.015)$ for BMI, 0.619 (95\% CI 0.55-0.68; $P=0.011)$ for WC, 0.556 (95\% CI 0.49-0.62; $P=0.233$ ) for total testosterone, 0.720 (95\% CI 0.65-0.77; $P<0.001)$ for DHEAS, 0.558 (95\% CI $0.49-0.62 ; P=0.219)$ for total cholesterol, 0.578 (95\% CI $0.51-0.64 ; P=0.097)$ for non-HDL cholesterol, $0.569(95 \%$ CI $0.50-0.63 ; P=0.142$ ) for triglycerides, 0.626 (95\% CI $0.54-0.70 ; P=0.019)$ for uric acid, and 0.760 (95\% CI 0.70 $0.81 ; P<0.001)$ for VAI (Table 3$)$. Among the variables that showed a significant C-statistic, the VAI and DHEAS showed a significantly greater area under the ROC curve (Table 4 and Fig. 1). The threshold levels, calculated by maximizing the combined specificity and sensitivity in the ROC curves, were 1.82 (sensitivity: $71.43 \%$ and specificity: $75.0 \%$ ) for VAI and $8.43 \mu \mathrm{mol} / 1$ (sensitivity: 71.43\% and specificity: $69.79 \%$ ) for DHEAS.

\section{Correlations between insulin sensitivity indices and DHEAS}

Given the association between DHEAS and diabetes shown, and considering the changes in DHEAS related to age and body weight $(25,26,27,28)$, some linear regression models were performed to evaluate the effect of DHEAS (adjusted for age and BMI) on the various parameters of insulin sensitivity and secretion examined. DHEAS correlated independently with $\mathrm{AUC}_{2} \mathrm{~h}$ glucose $(\beta=0.156, P=0.013)$ and DIO $(\beta=0.166, P=0.011)$; no correlation was found with HOMA2-IR $(\beta=-0.093$, $P=0.135)$, ISI Matsuda $(\beta=0.015, P=0.818)$, and $\operatorname{AUC}_{2 \mathrm{~h} \text { insulin }}(\beta=-0.047, P=0.464)$.

\section{Discussion}

Although it is known that a diagnosis of PCOS in adolescent and adult women confers up to a tenfold increased risk of developing T2DM $(6,7,8)$, our Sicilian Caucasian women with PCOS had a relatively low prevalence of T2DM (1.7\%). These data are comparable to reports in the literature of non-obese women with PCOS $(1-2 \%)(6,7,8)$, but 170 women $(70.5 \%)$ in our series had a higher BMI than $30 \mathrm{~kg} / \mathrm{m}^{2}$. Instead, what characterized

Table 4 Differences between C-statistics of the predictor variables of altered glucose tolerance (IFG or IGT or IFG + IGT or T2DM).

\begin{tabular}{|c|c|c|c|c|}
\hline & $\begin{array}{c}\text { Difference } \\
\text { between } \\
\text { C-statistics }\end{array}$ & S.E.M. & $95 \% \mathrm{Cl}$ & $\boldsymbol{P}$ \\
\hline BMI vs WC & 0.040 & 0.03 & -0.03 to 0.11 & 0.268 \\
\hline BMI vs DHEAS & 0.087 & 0.07 & -0.05 to 0.23 & 0.236 \\
\hline BMI vs uric acid & 0.016 & 0.06 & -0.10 to 0.13 & 0.781 \\
\hline BMI vs VAl & 0.161 & 0.06 & 0.03 to 0.29 & 0.014 \\
\hline WC vs DHEAS & 0.046 & 0.07 & -0.09 to 0.19 & 0.528 \\
\hline WC vs uric acid & 0.024 & 0.05 & -0.08 to 0.13 & 0.671 \\
\hline WC vs VAI & 0.121 & 0.05 & 0.01 to 0.22 & 0.028 \\
\hline DHEAS vs uric acid & 0.070 & 0.07 & -0.07 to 0.21 & 0.329 \\
\hline DHEAS vs VAI & 0.074 & 0.06 & -0.05 to 0.20 & 0.275 \\
\hline Uric acid vs VAI & 0.145 & 0.06 & 0.02 to 0.26 & 0.020 \\
\hline
\end{tabular}

WC, waist circumference; VAI, visceral adiposity index. 


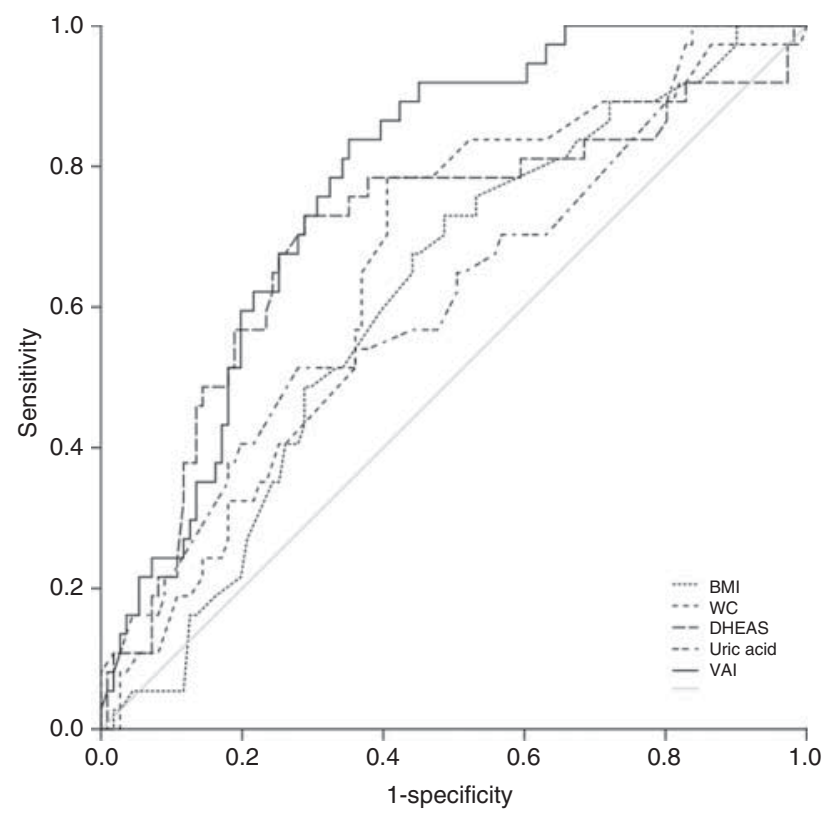

\section{Figure 1}

Comparison of ROC curves predictive of the composite endpoint (impaired fasting glucose (IFG), impaired glucose tolerance (IGT), IFG + IGT, and type 2 diabetes mellitus (T2DM)).

our women with PCOS was the high prevalence of prediabetes, especially IFG (11.6\%): these patients, as recommended by the diabetologic guidelines (20), should certainly be screened by an OGTT, regardless of whether they are affected by PCOS.

Given the high prevalence of PCOS in women of childbearing age, and given the known association with diabetes, several studies have attempted to identify simple screening tools that are alternatives to OGTT, usable in the case of normal fasting glucose. One of these is glycohemoglobin, which, however, has shown poor sensitivity for detecting IGT in women with PCOS $(29,30)$; therefore, it should only be considered a valid measure in the case of overt T2DM.

In our study, we identified two simple parameters that showed good sensitivity and specificity for detecting an altered glucose tolerance: the VAI (cutoff point: 1.82) and the DHEAS measuredinthe follicular phase (cutoff point: $8.43 \mu \mathrm{mol} / \mathrm{l})$.

With regard to the application of the VAI in women with PCOS, there are several studies that confirm it to be an indicator of cardiometabolic risk (31). In our first study (17), it was found that the oligo-menorrhoic phenotypes of PCOS (applying the Rotterdam criteria) were characterized by a high VAI and a condition of cardiometabolic risk. In young Korean women with PCOS, the VAI positively correlated with the visceral fat area (measured with computed tomography) and the visceralto-subcutaneous fat ratio, but negatively correlated with the insulin-mediated glucose utilization ( $M$ value) during euglycemic hyperinsulinemic clamp (32). Another recent study has demonstrated that the VAI increases in relation to the severity of anovulation, insulin resistance, and inflammation in women with PCOS (33). Recently, these findings have led us to verify whether it was possible to distinguish women with metabolically healthy PCOS (MH-PCOS) from women with metabolically unhealthy PCOS (MU-PCOS) using simple diagnostic tools such as BMI, waist-to-hip ratio, the at-risk category suggested by the Androgen Excess Society (34), and the VAI: among all the criteria studied a VAI $>1.675$ showed the best predictive value in detecting an adverse metabolic profile in women with PCOS (35).

Thus, by putting together the results from these previous studies with those of the present study, we can state that a VAI $>1.67$ is already indicative of a MU-PCOS and a VAI $>1.82$ is indicative of a MU-PCOS with a high risk of diabetes. Obviously, prospective studies over a period of at least 10 years are needed in order precisely to quantify this risk in the future.

With regard to the use of the DHEAS as a marker of diabetes risk in women with PCOS, the issue is more controversial than the VAI, suggesting that there are even studies showing a negative correlation between DHEAS and insulin resistance in women with PCOS (36) and in obese women with T2DM (37). In our study, not only did we find significantly higher DHEAS levels in the group with altered glucose tolerance, but also this parameter at ROC analysis showed a significant area under the ROC curve, which indicated good sensitivity and specificity for the identification of this group of patients.

It is known that elevated serum levels of DHEAS and 11 -hydroxyandrostenedione are found in 20-50\% of women with PCOS $(38,39,40,41)$ and these women show generalized hypersecretion of adrenocortical products (pregnenolone, 17-hydroxypregnenolone, DHEA, $\Delta 4$-androstenedione, and possibly cortisol) basally and in response to ACTH administration (42). Moreover, the increased levels of DHEAS may be the sole abnormality in circulating androgens observed in $\sim 10 \%$ of women with PCOS $(43,44)$. Therefore, it is difficult to think that this hyperactivity of the adrenal gland may play a protective role regarding the risk of diabetes in women with PCOS, as suggested by some evidences $(36,45)$. Certainly, the role of adrenal androgens in the metabolic 
disturbances of women with PCOS is unclear, considering that there are also studies suggesting a positive association between high DHEAS levels and metabolic disturbances such as hypertension $(46,47)$.

We feel that these hypotheses on the possible protective metabolic role of DHEAS in women with PCOS may be influenced by what is observed in postmenopausal women and even more in men, in which age-related reduction of DHEAS is associated with an increased cardiometabolic risk $(48,49)$.

In women with PCOS, the increase in DHEAS is to be observed mainly as a result of hyperinsulinism (compensating a state of insulin resistance), which is usually associated with the syndrome (50); it is known that administration of exogenous insulin appears to induce adrenocortical androgen production in women with PCOS through stimulation of 17-hydroxylase activity (50); moreover, a relationship between circulating insulin levels and hyperandrogenism in women with PCOS is further suggested by the ability of insulin-sensitizing drugs to reduce ovarian and adrenal androgen production $(51,52)$.

In our study, an association between DHEAS and indices of insulin sensitivity (HOMA2-IR, ISI Matsuda) was not found, but, surprisingly, DHEAS correlated positively with DIO, which expresses insulin secretion secondary to a certain degree of insulin sensitivity (i.e. compensatory hyperinsulinism) (23). This could be explained by insulin action on adrenal cortex: in women of childbearing age, the compensatory hyperinsulinism may play a synergistic role with ACTH with regard to the synthesis of DHEAS (50).

Among the limitations of this retrospective study, mention should be made of the sample size, which did not allow us to assess the predictive markers studied after subdividing women with PCOS into the different phenotypes derived from application of the Rotterdam criteria (the subdivision into four phenotypes did significantly reduce the statistical power of the study). Another limitation of the study is the use of antibody-based assays for steroid levels; in further studies, this limitation could be overcome by the use of liquid chromatographymass spectrometry, which in our hospital is rarely used at the moment due to the high costs of materials, the special skills required, and poor practicality for a large series of assays.

In conclusion, the VAI and DHEAS may be considered useful tools for prescreening in all women with PCOS with no obvious classical risk factors for diabetes (normal weight, absence of family history, and normal fasting glucose). In the future, further studies could also evaluate the usefulness of these tools even in those women who meet only one of the three diagnostic criteria of PCOS.

\section{Declaration of interest}

The authors declare that there is no conflict of interest that could be perceived as prejudicing the impartiality of the research reported.

\section{Funding}

This research did not receive any specific grant from any funding agency in the public, commercial or not-for-profit sector.

\section{References}

1 Asuncion M, Calvo RM, San Millan JL, Sancho J, Avila S \& EscobarMorreale HF. A prospective study of the prevalence of the polycystic ovary syndrome in unselected Caucasian women from Spain. Journal of Clinical Endocrinology and Metabolism 200085 2434-2438. (doi:10.1210/ jcem.85.7.6682)

2 Diamanti-Kandarakis E, Kouli CR, Bergiele AT, Filandra FA, Tsianateli TC, Spina GG, Zapanti ED \& Bartzis MI. A survey of the polycystic ovary syndrome in the Greek island of Lesbos: hormonal and metabolic profile. Journal of Clinical Endocrinology and Metabolism 1999 84 4006-4011. (doi:10.1210/jcem.84.11.6148)

3 Yildiz BO, Bozdag G, Yapici Z, Esinler I \& Yarali H. Prevalence, phenotype and cardiometabolic risk of polycystic ovary syndrome under different diagnostic criteria. Human Reproduction 201227 3067-3073. (doi:10.1093/humrep/des232)

4 Galluzzo A, Amato MC \& Giordano C. Insulin resistance and polycystic ovary syndrome. Nutrition, Metabolism, and Cardiovascular Diseases 2008 18 511-518. (doi:10.1016/j.numecd.2008.05.004)

5 Diamanti-Kandarakis E \& Dunaif A. Insulin resistance and the polycystic ovary syndrome revisited: an update on mechanisms and implications. Endocrine Reviews 201233 981-1030. (doi:10.1210/er.2011-1034)

6 Legro RS, Kunselman AR, Dodson WC \& Dunaif A. Prevalence and predictors of risk for type 2 diabetes mellitus and impaired glucose tolerance in polycystic ovary syndrome: a prospective, controlled study in 254 affected women. Journal of Clinical Endocrinology and Metabolism 199984 165-169. (doi:10.1210/jcem.84.1.5393)

7 Ehrmann DA, Barnes RB, Rosenfield RL, Cavaghan MK \& Imperial J. Prevalence of impaired glucose tolerance and diabetes in women with polycystic ovary syndrome. Diabetes Care 199922 141-146. (doi:10. 2337/diacare.22.1.141)

8 Palmert MR, Gordon CM, Kartashov AI, Legro RS, Emans SJ \& Dunaif A Screening for abnormal glucose tolerance in adolescents with polycystic ovary syndrome. Journal of Clinical Endocrinology and Metabolism 200287 1017-1023. (doi:10.1210/jcem.87.3.8305)

9 Alberti KG, Zimmet P \& Shaw J. International Diabetes Federation: a consensus on type 2 diabetes prevention. Diabetic Medicine 2007 24 451-463. (doi:10.1111/j.1464-5491.2007.02157.x)

10 American Association of Clinical Endocrinologists Polycystic Ovary Syndrome Writing Committee. American Association of Clinical Endocrinologists position statement on metabolic and cardiovascular consequences of polycystic ovary syndrome. Endocrine Practice 2005 11 126-134. (doi:10.4158/EP.11.2.125)

11 Salley KE, Wickham EP, Cheang KI, Essah PA, Karjane NW \& Nestler JE. Glucose intolerance in polycystic ovary syndrome - a position statement of the Androgen Excess Society. Journal of Clinical Endocrinology and Metabolism 200792 4546-4556. (doi:10.1210/ jc.2007-1549) 
12 Legro RS, Arslanian SA, Ehrmann DA, Hoeger KM, Murad MH, Pasquali R \& Welt CK. Diagnosis and treatment of polycystic ovary syndrome: an endocrine society clinical practice guideline. Journal of Clinical Endocrinology and Metabolism 201398 4565-4592. (doi:10.1210/ jc.2013-2350)

13 Hsu MI. Changes in the PCOS phenotype with age. Steroids $2013 \mathbf{7 8}$ 761-766. (doi:10.1016/j.steroids.2013.04.005)

14 Rotterdam ESHRE/ASRM-Sponsored PCOS Consensus Workshop Group. Revised 2003 consensus on diagnostic criteria and long-term health risks related to polycystic ovary syndrome (PCOS). Human Reproduction 200419 41-47. (doi:10.1093/humrep/deh098)

15 Ferriman D \& Gallwey JD. Clinical assessment of body hair growth in women. Journal of Clinical Endocrinology and Metabolism 196121 1440-1447. (doi:10.1210/jcem-21-11-1440)

16 Azziz R, Carmina E, Dewailly D, Diamanti-Kandarakis E, EscobarMorreale HF, Futterweit W, Janssen OE, Legro RS, Norman RJ, Taylor AE et al. The Androgen Excess and PCOS Society criteria for the polycystic ovary syndrome: the complete task force report. Fertility and Sterility 200991 456-488. (doi:10.1016/j.fertnstert.2008.06.035)

17 Amato MC, Verghi M, Galluzzo A \& Giordano C. The oligomenorrhoic phenotypes of polycystic ovary syndrome are characterized by a high visceral adiposity index: a likely condition of cardiometabolic risk. Human Reproduction 201126 1486-1494. (doi:10.1093/humrep/der088)

18 Christensen JT, Boldsen J \& Westergaard JG. Ovarian volume in gynecologically healthy women using no contraception, or using IUD or oral contraception. Acta Obstetricia et Gynecologica Scandinavica 1997 76 784-789. (doi:10.3109/00016349709024348)

19 Expert Panel on Detection, Evaluation, and Treatment of High Blood Cholesterol in Adults. Executive summary of the Third Report of the National Cholesterol Education Program (NCEP) 2001 Expert Panel on Detection, Evaluation, and Treatment of High Blood Cholesterol in Adults (Adult Treatment Panel III). Journal of the American Medical Association 2001285 2486-2497. (doi:10.1001/jama.285.19.2486)

20 American Diabetes Association. Standards of medical care in diabetes 2014. Diabetes Care 201437 (Suppl 1) S14-S80. (doi:10.2337/dc14-S014)

21 Vermeulen A, Verdonck L \& Kaufman JM. A critical evaluation of simple methods for the estimation of free testosterone in serum. Journal of Clinical Endocrinology and Metabolism 199984 3666-3672. (doi:10.1210/jcem.84.10.6079)

22 Matsuda M \& De Fronzo RA. Insulin sensitivity indices obtained from oral glucose tolerance testing: comparison with the euglycemic insulin clamp. Diabetes Care 200124 460-464. (doi:10.2337/diacare.24.3.460)

23 Utzschneider KM, Prigeon RL, Faulenbach MV, Tong J, Carr DB, Boyko EJ, Leonetti DL, McNeely MJ, Fujimoto WY \& Kahn SE. Oral disposition index predicts the development of future diabetes above and beyond fasting and 2-h glucose levels. Diabetes Care 200932 335-341. (doi:10.2337/dc08-1478)

24 Amato MC, Giordano C, Galia M, Criscimanna A, Vitabile S, Midiri M, Galluzzo A \& AlkaMeSy Study Group. Visceral adiposity index: a reliable indicator of visceral fat function associated with cardiometabolic risk. Diabetes Care 201033 920-922. (doi:10.2337/dc09-1825)

25 Orentreich N, Brind HL, Rixer RL \& Vogelman JH. Age changes and sex differences in serum dehydroepiandrosterone sulfate concentrations throughout adulthood. Journal of Clinical Endocrinology and Metabolism 198459 551-555. (doi:10.1210/jcem-59-3-551)

26 Fink RI, Kolterman OG, Griffin J \& Olefsky JM. Mechanism of insulin resistance in aging. Journal of Clinical Investigation 198371 1523-1535. (doi:10.1172/JCI110908)

27 Rowe JW, Minaker KL, Pallotta HA \& Flier JS. Characterization of the insulin resistance in aging. Journal of Clinical Investigation $1983 \mathbf{7 1}$ 1581-1587. (doi:10.1172/JCI110914)

28 Paolisso G, Ammendola S, Rotandi M, Gambardella A, Rizzo MR, Mazziotti G, Tagliamonte MR, Carella C \& Varricchio M. Insulin resistance and advancing age: what role for dehydroepiandrosterone sulfate? Metabolism 199746 1281-1286. (doi:10.1016/S00260495(97)90231-6)
29 Legro RS, Gnatuk CL, Kunselman AR \& Dunaif A. Changes in glucose tolerance over time in women with polycystic ovary syndrome: a controlled study. Journal of Clinical Endocrinology and Metabolism 2005 90 3236-3242. (doi:10.1210/jc.2004-1843)

30 Velling Magnussen L, Mumm H, Andersen M \& Glintborg D. Hemoglobin A1c as a tool for the diagnosis of type 2 diabetes in 208 premenopausal women with polycystic ovary syndrome. Fertility and Sterility 201196 1275-1280. (doi:10.1016/j.fertnstert.2011.08.035)

31 Amato MC \& Giordano C. Visceral adiposity index: an indicator of adipose tissue dysfunction. International Journal of Endocrinology 2014 730827. (doi:10.1155/2014/730827)

$32 \mathrm{Oh} \mathrm{JY}$, Sung YA \& Lee HJ. The visceral adiposity index as a predictor of insulin resistance in young women with polycystic ovary syndrome. Obesity 201321 1690-1694. (doi:10.1002/oby.20096)

33 Androulakis K, Kandaraki E, Christakou C, Karachalios A, Marinakis E, Paterakis T \& Diamanti-Kandarakis E. Visceral adiposity index (VAI) is related to the severity of anovulation and other clinical features in women with polycystic ovary syndrome. Clinical Endocrinology 201481 426-431. (doi:10.1111/cen.12447)

34 Wild RA, Carmina E, Diamanti-Kandarakis E, Dokras A, EscobarMorreale HF, Futterweit W, Lobo R, Norman RJ, Talbott E \& Dumesic DA. Assessment of cardiovascular risk and prevention of cardiovascular disease in women with the polycystic ovary syndrome: a consensus statement by the Androgen Excess and Polycystic Ovary Syndrome (AE-PCOS) Society. Journal of Clinical Endocrinology and Metabolism 201095 2038-2049. (doi:10.1210/jc.2009-2724)

35 Amato MC, Guarnotta V, Forti D, Donatelli M, Dolcimascolo S \& Giordano C. Metabolically healthy polycystic ovary syndrome (MH-PCOS) and metabolically unhealthy polycystic ovary syndrome (MU-PCOS): a comparative analysis of four simple methods useful for metabolic assessment. Human Reproduction 201328 1919-1928. (doi:10.1093/humrep/det105)

36 Brennan K, Huang A \& Azziz R. Dehydroepiandrosterone sulfate and insulin resistance in patients with polycystic ovary syndrome. Fertility and Sterility 200991 1848-1852. (doi:10.1016/j.fertnstert.2008.02.101)

37 Mottl R \& Cerman J. A relationship between dehydroepiandrosterone sulfate and insulin resistance in obese men and women. Vnitrní Lékarství 200450 923-929.

38 Hoffman DI, Klove K \& Lobo RA. The prevalence and significance of elevated dehydroepiandrosterone sulfate levels in anovulatory women. Fertility and Sterility $1984 \mathbf{4 2}$ 76-81.

39 Steinberger E, Smith KD \& Rodriguez-Rigau LJ. Testosterone, dehydroepiandrosterone, and dehydroepiandrosterone sulfate in hyperandrogenic women. Journal of Clinical Endocrinology and Metabolism 198459 471-477. (doi:10.1210/jcem-59-3-471)

40 Carmina E, Rosato F \& Janni A. Increased DHEAs levels in PCO syndrome: evidence for the existence of two subgroups of patients. Journal of Endocrinological Investigation 19869 5-9. (doi:10.1007/ BF03348052)

41 Hague WM, Honour JW, Adams J, Vecsei P \& Jacobs HS. Steroid responses to ACTH in women with polycystic ovaries. Clinical Endocrinology 198930 355-365. (doi:10.1111/j.1365-2265.1989. tb00433.x)

42 Yildiz BO \& Azziz R. The adrenal and polycystic ovary syndrome. Reviews in Endocrine \& Metabolic Disorders 20078 331-342. (doi:10.1007/ s11154-007-9054-0)

43 Chang WY, Knochenhauer ES, Bartolucci AA \& Azziz R. Phenotypic spectrum of polycystic ovary syndrome: clinical and biochemical characterization of the three major clinical subgroups. Fertility and Sterility 200583 1717-1723. (doi:10.1016/j.fertnstert.2005.01.096)

44 Knochenhauer ES, Key TJ, Kahsar-Miller M, Waggoner W, Boots LR \& Azziz R. Prevalence of the polycystic ovary syndrome in unselected black and white women of the southeastern United States: a prospective study. Journal of Clinical Endocrinology and Metabolism 199883 3078-3082. (doi:10.1210/jcem.83.9.5090) 
45 Lerchbaum E, Schwetz V, Giuliani A, Pieber TR \& Obermayer-Pietsch B. Opposing effects of dehydroepiandrosterone sulfate and free testosterone on metabolic phenotype in women with polycystic ovary syndrome. Fertility and Sterility 201298 1318-1325. (doi:10.1016/j.fertnstert.2012.07.1057)

46 Schunkert H, Hense HW, Andus T, Riegger GA \& Straub RH. Relation between dehydroepiandrosterone sulfate and blood pressure levels in a populationbased sample. American Journal of Hypertension 199912 1140-1143. (doi:10.1016/S0895-7061(99)00128-4)

47 Hautanen A, Manttari M, Manninen V, Tenkanen L, Huttunen JK, Frick MH \& Adlercreutz H. Adrenal androgens and testosterone as coronary risk factors in the Helsinki Heart Study. Atherosclerosis 1994 105 191-200. (doi:10.1016/0021-9150(94)90049-3)

48 Ohlsson C, Vandenput L \& Tivesten A. DHEA and mortality: what is the nature of the association? Journal of Steroid Biochemistry and Molecular Biology 2014. In press. (doi:10.1016/j.jsbmb.2014.03.006)

49 Tchernof A \& Labrie F. Dehydroepiandrosterone, obesity and cardiovascular disease risk: a review of human studies. European Journal of Endocrinology 2004151 1-14. (doi:10.1530/eje.0.1510001)
50 Moghetti P, Castello R, Negri C, Tosi F, Spiazzi GG, Brun E, Balducci R, Toscano V \& Muggeo M. Insulin infusion amplifies 17- $\alpha$ hydroxycorticosteroid intermediates response to adrenocorticotropin in hyperandrogenic women: apparent relative impairment of 17,20-lyase activity. Journal of Clinical Endocrinology and Metabolism 199681 881-886. (doi:10.1210/jcem.81.3.8772544)

51 Arslanian SA, Lewy V, Danadian K \& Saad R. Metformin therapy in obese adolescents with polycystic ovary syndrome and impaired glucose tolerance: amelioration of exaggerated adrenal response to adrenocorticotropin with reduction of insulinemia/insulin resistance. Journal of Clinical Endocrinology and Metabolism 200287 1555-1559. (doi:10.1210/jcem.87.4.8398)

52 Ortega-Gonzalez C, Luna S, Hernandez L, Crespo G, Aguayo P, ArteagaTroncoso G \& Parra A. Responses of serum androgen and insulin resistance to metformin and pioglitazone in obese, insulin-resistant women with polycystic ovary syndrome. Journal of Clinical Endocrinology and Metabolism 200590 1360-1365. (doi:10.1210/ jc.2004-1965)

Received 17 July 2014

Revised version received 22 September 2014

Accepted 22 October 2014 